\title{
ENFERMAGEM PRÉ-HOSPITALAR NO SUPORTE BÁSICO DE VIDA: POSTULADOS ÉTICO-LEGAIS DA PROFISSÃO*
}

\author{
Antônio César Ribeiro ${ }^{1}$, Yanna Baralle Silva²
}

\begin{abstract}
RESUMO: Objetivou discutir a forma de organização do trabalho de enfermagem na assistência pré-hospitalar, considerando a caracterização das ocorrências atendidas por uma Unidade de Suporte Básico, à luz da legislação que regulamenta e disciplina o exercício profissional da categoria no Brasil. Estudo descritivo, retrospectivo, realizado junto ao Serviço de Atendimento Móvel de Urgência em Cuiabá-MT. Os dados foram coletados a partir das fichas dos atendimentos realizados no primeiro trimestre de 2013. Foram analisadas 926 ocorrências, constando-se que tanto os agravos quanto as ações de enfermagem se configuram majoritariamente como situações complexas, demandando competências técnicas e legais para a tomada de decisão, o que remete à necessidade da presença do enfermeiro. Considerou-se assim que a forma de organização da atenção préhospitalar, normatizada pelo Ministério da Saúde, afronta a legislação da enfermagem brasileira e que os profissionais que respondem tecnicamente pelo trabalho de enfermagem ou nela atuam, infringem postulados ético-legais da profissão.
\end{abstract}

DESCRITORES: Enfermagem; Legislação de Enfermagem; Atendimento de Emergência Pré-Hospitalar.

\section{PRE-HOSPITAL NURSING IN BASIC LIFE SUPPORT: ETHICAL AND LEGAL POSTULATES OF THE PROFESSION}

ABSTRACT: The aim of this study was to discuss how nursing work is organized in pre-hospital care, considering the characterization of incidents assisted by a Basic Support Unit, observing the legislation that regulates this category's professional practice in Brazil. A descriptive, retrospective study conducted with the Emergency Mobile Care Service in Cuiabá, state of Mato Grosso. Data were gathered from the records of incidents from the first quarter of 2013. A total of 926 incidents were analyzed, and showed that injuries and nursing care are mostly of a complex nature, demanding technical and legal competencies for decision making, which takes us back to the necessary presence of a nurse. Thus, the model of organization of pre-hospital care, standardized by the Ministry of Health, is against the Brazilian nursing's legislation and workers who are technically responsible for nursing work or whose practice in nursing infringe upon the ethical and legal postulates of the profession.

DESCRIPTORS: Nursing; Nursing legislation; Emergency medical services.

\section{ENFERMERÍA PREHOSPITALARIA EN SOPORTE BÁSICO DE VIDA: POSTULADOS ÉTICO-LEGALES DE LA PROFESIÓN}

RESUMEN: Se objetivó discutir formas de organización del trabajo de enfermería en atención Prehospitalaria, considerando la caracterización de los eventos atendidos por una Unidad de Soporte Básico, de acuerdo a legislación que reglamenta y disciplina el ejercicio profesional de la categoría en Brasil. Estudio descriptivo, retrospectivo, realizado con el Servicio de Atención Móvil de Urgencias en Cuiabá-MT. Datos recolectados de fichas de atenciones realizadas en el primer trimestre de 2013 . Fueron analizados 926 registros, constatándose que tanto los eventos como las acciones de enfermería configuran mayoritariamente acciones complejas, demandando competencias técnicas y legales para toma de decisiones, lo cual remite a la necesidad de presencia del enfermero. Se consideró así que la organización de la atención Prehospitalaria, normada por el Ministerio de Salud, se contrapone con la legislación de enfermería brasileña, y que los profesionales técnicamente responsables por el trabajo o actuantes en enfermería, infringen postulados ético-legales de la profesión.

DESCRIPTORES: Enfermería; Legislación de Enfermería; Servicios Médicos de Urgencia.

*Artigo extraído do Trabalho de Conclusão de Curso intitulado: " Caracterização dos atendimentos de uma unidade BRAVO/ SAMU e sua relação com a equipe de enfermagem “. Universidade Federal de Mato Grosso. 2014.

${ }^{1}$ Enfermeiro. Doutor em Ciências. Docente da Faculdade de Enfermagem da Universidade Federal de Mato Grosso. Cuiabá, MT, Brasil.

${ }^{2}$ Discente de Enfermagem. Universidade Federal de Mato Grosso. Cuiabá, MT, Brasil. 


\section{- INTRODUÇÃO}

O Serviço de Atendimento Móvel de Urgência (SAMU) constitui-se como parte integrante da Política Nacional de Urgências e Emergências, tendo por finalidade organizar o atendimento pré-hospitalar na rede pública ${ }^{(1)}$.

Instituído em todo o Território Nacional, o SAMU teve suas diretrizes redefinidas em 2012 e tem como objetivo atender precocemente as vítimas de agravos à saúde de qualquer natureza que podem causar sofrimento e/ou deixar sequelas, ou, levar a vítima a óbito. Assim, o serviço de atendimento préhospitalar está à disposição da sociedade ${ }^{(1-2)}$.

O SAMU é estruturado por uma Central de Regulação das Urgências, constituída por profissionais capacitados para a triagem dos casos que demandam orientação e/ou atendimento de urgência, ordenado por fluxo dentro de um sistema de referência e contra referência. Suas atividades técnicas são coordenadas por médicos reguladores com base nas informações colhidas dos usuários, que gerenciam e definem a operacionalização dos meios disponíveis para responder a tais solicitações, utilizando-se de protocolos técnicos e do poder de decisão em arbitrar sobre os equipamentos de saúde necessários ao adequado atendimento às vítimas ${ }^{(2)}$.

A partir da redefinição de suas diretrizes, o SAMU é organizado em Unidades de Suporte Básico de Vida Terrestre (BRAVO), Unidades de Suporte Avançado de Vida Terrestre (ALFA), Equipes Aeromédicas, Equipes de Embarcação, Motolâncias e Veículos de Intervenção Rápida ${ }^{(2)}$.

Conforme Norma Técnica do Ministério da Saúde $(\mathrm{NT}-\mathrm{MS})^{(2)}$, as unidades do tipo ALFA devem ter suas equipes constituídas por um profissional médico, um enfermeiro e um condutor (motorista da ambulância treinado para o suporte básico de vida); as do tipo BRAVO podem ter suas equipes constituídas por um auxiliar de enfermagem ou técnico de enfermagem, e um condutor. Já as Motolâncias podem ser conduzidas por um profissional de nível médio ou superior em enfermagem, com treinamento específico.

A enfermagem, como integrante das equipes que compõem o SAMU em todas as suas formas de organização, tem suas ações regulamentadas em legislação específica, definidora das competências legais de cada um dos seus profissionais. Neste sentido, é privativo do enfermeiro o atendimento a pacientes em risco de morte, nas situações que demandam tomadas de decisão imediata ${ }^{(3)}$.

No Brasil a regulação/regulamentação técnica, a partir de mandamentos legais específicos, e a fiscalização do exercício das profissões são delegadas pelo Estado às próprias corporações. Neste sentido, a Lei N. ${ }^{\circ}$ 5.905/1973 instituiu o Conselho Federal de Enfermagem (COFEN) e seus Regionais, que, na qualidade de autarquias federais, respondem pelo disciplinamento profissional do enfermeiro e das demais profissões compreendidas nos serviços de enfermagem ${ }^{(4)}$.

Assim, reafirmando o sentido da legislação regulamentadora do exercício profissional da enfermagem brasileira (LEPE), relativo ao atendimento pré-hospitalar e inter-hospitalar, o COFEN disciplinou as competências técnicas e legais dos seus profissionais estabelecendo que a assistência de enfermagem, independente do risco ser conhecido ou não, somente será desenvolvida com a presença do enfermeiro. Neste sentido, reafirma que as atividades desenvolvidas por técnicos e auxiliares de enfermagem deverão estar sob a supervisão direta do enfermeiro ${ }^{(3,5)}$.

Relativo às competências legais dos profissionais de nível médio da enfermagem, na LEPE dispõe que o técnico de enfermagem "[...] exerce atividades de nível médio, envolvendo orientação e acompanhamento do trabalho de Enfermagem em grau auxiliar, e participação no planejamento da assistência de Enfermagem [...]". Já o auxiliar de enfermagem "[...] exerce atividades de nível médio, de natureza repetitiva, envolvendo serviços auxiliares de Enfermagem sob supervisão, bem como a participação em execução simples" (3).

Assim, o presente estudo teve por objetivo discutir a forma de organização do trabalho de enfermagem na assistência pré-hospitalar, a partir da caracterização das ocorrências atendidas por uma Unidade de Suporte Básico de Vida Terrestre, integrante da Central de Regulação do SAMU Cuiabá-MT, considerando as normas legais que regulamentam e disciplinam o exercício da profissão no Brasil(3-7). 


\section{METODOLOGIA}

Trata-se de um estudo descritivo, retrospectivo, realizado junto a uma das Unidades BRAVO, integrante da Central do SAMU, em Cuiabá - MT.

Na Região Metropolitana do município, o SAMU está organizado em três níveis de atendimento: ALFA, BRAVO e Motolância(2). Sua Central de Regulação responde por três unidades de suporte avançado, sete unidades de suporte básico e duas motolâncias, para atender à Grande Cuiabá, o que inclui os municípios de Várzea Grande, Poconé e Chapada dos Guimarães.

Em que pese a regulamentação do Ministério da Saúde ${ }^{(2)}$, em Cuiabá-MT as equipes do tipo BRAVO são compostas por dois profissionais de enfermagem e um condutor.

Entre as unidades de suporte básico de vida terrestre, foi escolhida a BRAVO III, que tem sua base localizada em uma Unidade de Pronto Atendimento (UPA). A escolha desta unidade foi aleatória, dadas as características semelhantes que guarda entre as demais no que se refere à dimensão do território e composição das equipes, considerando-se a facilidade de acesso dos pesquisadores. Sua equipe conta com 12 profissionais de enfermagem, dois enfermeiros e 10 técnicos de enfermagem, que estão distribuídos em escala cujas equipes são compostas por dois destes profissionais e um condutor. Segundo a Gerência de Enfermagem da Central, a presença de enfermeiros na escala das unidades do tipo BRAVO é eventual e atende às necessidades pessoais de lotação destes, não observando um critério técnico para as suas alocações nas equipes.

Os dados relativos à caracterização dos agravos foram coletados das fichas de atendimento padronizadas pela Central do SAMU/Cuiabá-MT. Assim, foi considerado como critério de inclusão as fichas dos atendimentos realizados pela Unidade BRAVO III, com preenchimento total ou parcial, no período compreendido entre janeiro e março de 2013. Como na unidade estudada foi identificada a presença eventual de enfermeiros compondo as equipes, estabeleceu-se como critério de exclusão as fichas cujos atendimentos foram realizados com a participação destes.

Das fichas selecionadas, foram consideradas as informações de natureza objetiva (idade, sexo, natureza do agravo, detalhamento da causa externa, exame clínico, sinais vitais, Glasgow, procedimentos realizados, administração de medicamentos, destino da vítima e composição da equipe) e subjetiva (avaliação, diagnóstico, evolução/intercorrências).

Para a variável "sinais vitais" foi considerado se o seu preenchimento foi total, parcial ou sem registro e não os valores relativos às condições clínicas da vítima. Para tal avaliação optou-se pela escala de coma de Glasgow, cujo escore mínimo é 3 e o máximo é 15, sendo dividida em três parâmetros: abertura ocular (1 a 4), resposta verbal (1 a 5) e resposta motora (1 a 6) ${ }^{(8)}$. Na variável "composição da equipe" foi considerada a presença de um ou dois trabalhadores de enfermagem mais o condutor, ou sem registro.

Após o levantamento dos dados, estes foram sistematizados e digitados constituindo um banco de dados com os recursos do programa EpiData 3.1 Os dados foram analisados considerando sua distribuição e frequência.

A análise e discussão dos resultados foram realizadas à luz das normas técnicas do Ministério da Saúde ${ }^{(1-2)}$ que normatizam a organização do SAMU e dos mandamentos legais que regulamentam o exercício da enfermagem brasileira ${ }^{(3-7)}$.

Todos os procedimentos metodológicos foram considerados do ponto de vista ético e, neste sentido, o projeto matricial foi submetido e aprovado pelo Comitê de Ética em Pesquisa com Seres Humanos do Hospital Universitário Júlio Müller/UFMT, com o Parecer N. .o 427.039, de 17/10/2013.

\section{RESULTADOS}

No período compreendido entre janeiro e março de 2013, foram efetivamente realizados 1007 atendimentos pela unidade BRAVO III do SAMU/Cuiabá-MT. Destes, foram desconsiderados 81 
atendimentos, cujas equipes contavam com a presença eventual de um enfermeiro, sendo consideradas $926(91,95 \%)$ abordagens realizadas.

Dos casos atendidos, 495 (53,5\%) foram a vítimas do sexo masculino. Quanto à natureza dos agravos, sobressaíram os de causas externas, com 435 (47\%); seguidos pelos agravos de natureza clínica em adultos, com 240 (25,8\%). Os demais atendimentos registrados somaram 93 (10,1\%), distribuídos entre casos psiquiátricos, gineco/obstétricos, pediátricos e outros não especificados. Chamou a atenção o expressivo número de casos sem qualquer registro quanto à sua natureza, com 158 (17,1\%).

Dos registros relativos especificamente às causas externas, destacaram as colisões entre carro e moto, com 210 (48,3\%); as quedas de moto, com 74 (17\%); e quedas de nível, com 57 (13,1\%); seguidas por outros eventos com menor expressão.

Do universo de 240 casos de natureza clínica no geral, oito (3,2\%) foram registrados, onde destacaram a hipertensão arterial, com dois $(0,8 \%)$ e hipertensão arterial associada com acidente vascular encefálico, com dois $(0,8 \%)$.

A partir da variável exame clínico, constatou-se que 908 (98,1\%) das ocorrências não continham nenhum registro relativo às condições das vítimas. Relativo especificamente aos sinais vitais, cuja análise limitou-se ao registro ou não dos dados das vítimas, observou-se que apenas 60 (6,5\%) das ocorrências as equipes haviam preenchido a sua totalidade, que inclui os dados relativos ao pulso, pressão arterial, respiração, temperatura. Entre os demais, 482 (52,1\%), apresentaram preenchimento parcial e $384(41,4 \%)$ sem nenhum registro.

Já com relação à variável escala de coma de "Glasgow"(8), cuja análise buscou identificar o registro das condições clínicas das vítimas, a quantidade de fichas sem registro se destacou com 897 (97\%) do total.

Entre os registros encontrados, observou-se maior expressão dos escores 15, com $17(1,8 \%) ; 14$, com seis $(0,6 \%)$; e 3 , com três $(0,3 \%)$, seguidos pelos escores $11,9,6$, todos com um $(0,1 \%)$ registro.

Relativo aos procedimentos, estes foram tomados por ficha de atendimento e considerados conforme o atendimento ofertado às vítimas. Assim, do total das ocorrências, 770 (83,4\%) não continham nenhum registro sobre os procedimentos realizados. Entre aqueles registrados, os mais identificados foram: prancha rígida + colar cervical, com 92 (9,9\%); seguidos por curativo, com 18 (1,9\%); somente prancha rígida, com 12 (1,3\%); Prancha rígida + Colar cervical + Tala + Tração, com sete $(0,8 \%)$; entre outros com menor expressão. Em 25 (2,7\%) dos atendimentos houve registro de administração de medicamento como parte dos procedimentos realizados.

Dentre as ocorrências em que houve o deslocamento das equipes, pode-se observar os seguintes desfechos, pré ou pós-atendimento: evasão da vítima do local, recusa do atendimento, vítima atendida e liberada, remoção da vítima pelo SAMU, remoção da vítima por terceiros, óbito da vítima no local e sem registro do desfecho. Do total das ocorrências $653(70,5 \%)$ foram removidos pelo SAMU para alguma unidade de atendimento de referência. Entre as demais, $121(13,1 \%)$ ficaram sem registro acerca do desfecho do caso e/ou destinos da vítima e, com menor expressão, foram registrados 73 (7,9\%) como tendo sido atendidas no local e liberadas; 58 (6,3\%) como recusa no atendimento; 11 (1,2\%) como tendo sido removidas por terceiros; oito ( $8 \%$ ) com óbito no local e dois $(0,2 \%)$ que evadiram-se do local antes da chegada da equipe.

Na análise das informações subjetivas contidas nas fichas, percebeu-se que os dados inseridos, tanto na avaliação quanto na evolução/intercorrência, possuíam as mesmas características de descrição do acidente e/ou estado da vítima, sendo frequentemente repetidos em ambos os campos. Já em relação ao diagnóstico, das fichas analisadas, não foi encontrado nenhum registro.

\section{- DISCUSSÃO}

De início, pôde-se observar que, conforme achados de outros estudos que buscaram a caracterização das ocorrências demandadas ao SAMU, tem maior expressão aquelas atendidas pelas Unidades de Suporte Básico de Vida Terrestre (USB), o que coloca este nível de assistência no centro da organização 
deste serviço ${ }^{(9-11)}$.

Neste estudo, que se limitou aos atendimentos de uma das unidades BRAVO, observou-se que na distribuição dos atendimentos, tanto pela natureza do agravo quanto pelo sexo das vítimas, os resultados encontrados assemelham-se com outros estudos, locais e nacionais, que buscaram a mesma caracterização $^{(11-13)}$, com a concentração de $47 \%$ e 25,9\% de casos relacionados às causas externas e casos clínicos, respectivamente, e 53,5\% de atendimentos à vítimas do sexo masculino. Faz exceção os estudos realizados nas Regiões Sul e Sudeste onde os casos de natureza clínica ganham destaque ${ }^{(10,14)}$.

Quando analisada a distribuição dos eventos por causas externas, destacam-se os acidentes de trânsito, relacionados às colisões entre carro e moto, com 52,1\%; seguidas pelas quedas de moto, com 17,4\%; e pela queda de nível com 14,9\%, outros estudos confirmam a importância epidemiológica destes agravos ${ }^{(11-13,15)}$. São situações em que o cenário a ser encontrado pela equipe é desconhecido e imprevisível e cujas vítimas requerem minuciosa avaliação primária, com a decisão qualificada sobre os primeiros atendimentos e encaminhamentos dentro de um sistema de referência ao atendimento ao trauma. As vítimas necessitam ser estabilizadas e imobilizadas de forma adequada, com o objetivo de manter as condições vitais, diminuir e/ou evitar agravamento do quadro clínico e/ou sequelas, o que requer habilidade e competência técnica ${ }^{(15)}$.

Chamou atenção os dados relativos à variável exame clínico, cujos resultados dependem da percepção e capacidade técnica de avaliação da vítima. Neste caso, constatou-se que 98,1\% das ocorrências não continham nenhum registro relativo às condições das vítimas. Sobre os sinais vitais, que compõem a avaliação clínica e cuja prática de verificação é uma ação de rotina em qualquer serviço de enfermagem, no âmbito hospitalar para o paciente em situação de internação ou em ambulatório, observou-se que apenas $6,5 \%$ das ocorrências as equipes haviam preenchido a sua totalidade; em $52,1 \%$ apenas o preenchimento parcial; e em $41,5 \%$ das fichas não constava qualquer registro.

Ainda relacionado à avaliação da vítima, tem-se a escala de coma de Glasgow como um potente recurso técnico para avaliação na assistência pré-hospitalar em situação de trauma. Utilizada mundialmente para avaliar o nível de consciência, é prática e permite a compreensão no processo de comunicação técnica para tomada de decisão e conduta qualificada por parte da Central de Regulação ${ }^{(8)}$. Sobre estas informações, constatou-se que em 96,9\% das ocorrências não havia qualquer referência a estes parâmetros.

De acordo com a National Association of Emergency Medical Techinicians, no atendimento à vítima de trauma, deve-se considerar três fases de avaliação: o que levou a colisão (uso de substâncias lícitas ou ilícitas, condições preexistentes); análise do impacto da colisão, que pode ser divido em três tipos (colisão dos dois objetos; colisão das vítimas com o veículo; e o impacto dos órgãos dentro da vítima) e, por fim, a consolidação dos anteriores pelo socorrista, que se avalia as possíveis complicações advindas do acidente, para a tomada de decisão acerca das condutas a serem realizadas ${ }^{(8)}$.

Os dados relativos à natureza dos agravos atendidos pelas equipes de enfermagem, conforme apresentados, demonstram que o tipo de intervenção demandada está longe de ser considerada como ação de natureza repetitiva e/ou de grau auxiliar, conforme traz a lei do exercício profissional acerca das atribuições dos agentes de nível médio do trabalho de enfermagem ${ }^{(3)}$.

O propósito do SAMU está na manutenção da vida, com oferta de suporte básico ou avançado e o transporte seguro até um serviço de saúde que reúna tecnologia adequada a cada situação particular, o que demanda apurada avaliação e tomada de decisão sobre o atendimento e consequente encaminhamento ${ }^{(1-2)}$.

Na medida em que a atenção de enfermagem em situação de urgência/emergência pré-hospitalar requer minuciosa avaliação clínica para tomada de decisão imediata, no sentido da escolha da melhor conduta, visando atender às necessidades da vítima, quer no sentido de saná-las ou antecipá-las, tal prática evoca a participação do profissional enfermeiro por ser este o único possuidor de tal competência legal ${ }^{(3,5)}$.

Sobre os procedimentos realizados, que poderiam caracterizar qualitativamente o cuidado de enfermagem na assistência pré-hospitalar, observou-se que em 83,2\% não havia nenhuma referência ao cuidado prestado. Entre os parcos registros, dada a prevalência dos agravos decorrentes de causas 
externas, sobressaíram as ações relativas à imobilização e transporte, ofertados a $92(9,9 \%)$ dos casos, seguidas por curativos $18(1,9 \%)$.

Devido à natureza das ocorrências, esperava-se que a variável procedimentos realizados apresentasse um quantitativo significativo de registros que pudessem caracterizar a prática da enfermagem, porém, constatou-se a quase ausência destes, o que pode estar relacionado a dois motivos particulares: (1) dificuldades no preenchimento da ficha, motivadas pela própria dinâmica do trabalho; ou a (2) não realização dos procedimentos padronizados para este tipo de atendimento ${ }^{(10)}$.

Outra situação constatada como característica da assistência de enfermagem e que afronta a legislação de enfermagem, ainda que com pouca expressão, foi a administração de medicamentos realizada sem a supervisão direta do enfermeiro a partir da prescrição verbal do médico regulador, em $25(2,7 \%)$ atendimentos ${ }^{(6)}$.

Nesta última situação, segundo a norma do COFEN, restam duas considerações: (1) o enfermeiro que realizar a administração de medicamento numa situação de urgência e emergência, deve, obrigatoriamente, elaborar um relatório meticuloso e detalhado sobre as circunstâncias que o levaram a praticá-la, porém, os registros analisados não continham informações suficientes para se determinar a gravidade dos agravos e a situação que os levou a cometer tal ato; (2) as situações de risco iminente de morte demandam ações de intervenções complexas, o que, inequivocamente, requer a presença do enfermeiro ${ }^{(3,5-6)}$.

É certo que todos os profissionais integrantes das equipes de resgate passam por treinamentos específicos, atendendo às normas técnicas do Ministério da Saúde ${ }^{(2)}$. Porém, em que pese a capacitação assegurada aos agentes do trabalho de enfermagem, como condição para sua atuação nas equipes de resgate, há que se considerar que a construção de uma competência técnica, pela via do treinamento pontual, não pode prescindir da competência legal expressa em lei. O fato do trabalhador de enfermagem de nível médio passar pelo processo continuado de capacitação não confere a este prerrogativas legais distintas daquelas contidas no regulamento profissional ${ }^{(3,5-7)}$.

Quando o Ministério da Saúde brasileiro define que para uma unidade BRAVO a equipe pode ser composta por um técnico ou auxiliar de enfermagem e um condutor ${ }^{(2)}$, fica subentendido que estes profissionais assumem integralmente o processo de assistência, inclusive emitindo pareceres sobre a condição clínica das vítimas que vão orientar o médico regulador na tomada de decisão para os mais variados casos.

O enfermeiro é imprescindível no atendimento pré-hospitalar como qualificador da assistência de enfermagem prestada nas mais diferentes situações encontradas, evidenciando a necessidade deste como líder nas equipes de suporte básico ${ }^{(5,16-18)}$.

Quanto ao destino dos casos atendidos, notou-se que em $73(7,9 \%)$ ocorrências o técnico de enfermagem, sob a orientação do médico regulador, liberou a vítima em detrimento do seu encaminhamento após o atendimento, sem removê-la para a unidade de saúde de referência. Nestes casos, o comando pela liberação é decidido pela Central de Regulação a partir das informações produzidas pela avaliação clínica realizada pelo profissional de nível médio de enfermagem. Nunca será demais reafirmar que o agente de nível médio do trabalho de enfermagem, além de não possuir a competência legal ${ }^{(3,5)}$, não possui a competência técnica para avaliar clinicamente a vítima e induzir a tomada de decisão do médico pela alta ou encaminhamento.

Frente às evidências relativas à composição das equipes e os atendimentos realizados por estas, evocamos o sentido da prática ética codificada pela categoria. O Código de Deontologia dos profissionais de enfermagem estabelece que o profissional somente deve aceitar atribuições para as quais tenha competência técnica e legal, fato que coloca os técnicos de enfermagem numa condição eticamente questionável ${ }^{(7)}$.

Por outro lado, deve-se considerar que a alocação dos técnicos de enfermagem para responderem sozinhos pelos atendimentos nas equipes BRAVO é de competência do enfermeiro Responsável Técnico pela organização e funcionamento da assistência de Enfermagem no SAMU. Neste sentido, quando este o faz, ainda que seguindo orientações das normas emanadas pelo Ministério da Saúde ${ }^{(2)}$, infringe outro dispositivo ético que pró́be a delegação de funções próprias do enfermeiro aos 
profissionais de nível médio ${ }^{(7)}$.

O código de ética de enfermagem ainda dispõe que é obrigação dos seus profissionais notificar ao Conselho Regional quando impedido do exercício da profissão conforme seus preceitos legais, colocando ainda como proibição a participação ou conivência com situações que contrariam postulados éticos e legais da prática profissional ${ }^{(7)}$.

Frente às evidências encontradas, no que se refere à organização da assistência de enfermagem no SAMU ${ }^{(1-2)}$, resta a consideração de que o Ministério da Saúde prescindiu da legislação profissional da enfermagem brasileira ${ }^{(3,5-7)}$ quando formulou as normas técnicas relativas à organização desse serviço, o que, além de afrontá-la, contribui para a sua baixa institucionalidade.

\section{CONSIDERAÇÕES FINAIS}

Esta pesquisa possibilitou a constatação de que a natureza dos agravos atendidos pelas unidades BRAVO/SAMU estão longe de serem consideradas como de natureza simples.

Neste sentido, toda a regulamentação profissional da enfermagem brasileira é inequívoca quando prescreve que os agentes de nível médio do trabalho de enfermagem só podem exercer suas funções sob a supervisão direta do enfermeiro. Assim, a forma de organização das Unidades de Suporte Básico para o atendimento pré-hospitalar, definida pelo Ministério da Saúde, afronta o conteúdo legal que regulamenta o exercício profissional da enfermagem brasileira.

O fato de um auxiliar ou técnico de enfermagem ser alocado formalmente e com respaldo de uma norma técnica do Ministério da Saúde para a assunção de funções que são próprias do enfermeiro sugere a violabilidade do mercado de trabalho deste último, o que coloca em questão o sentido do profissionalismo da enfermagem brasileira, na ótica da sociologia das profissões.

Ainda que o presente estudo apresente limitações, se considerada a dimensão que a temática assume, seus resultados sugerem à enfermagem brasileira reflexão acerca do seu trabalho e a violabilidade do território profissional do enfermeiro, na perspectiva da sua condição profissional no contexto estudado.

Sugere-se assim que outros estudos possam ser realizados no sentido da ampliação eaprofundamento da temática, o que inclui outros setores/cenários de atuação do enfermeiro no campo da saúde.

\section{REFERÊNCIAS}

1. Portaria $n^{\circ} 1.600$ Ministério da Saúde, de 7 de julho de 2011 (BR) [internet]. Reformula a política nacional de atenção às urgências e institui a rede de atenção às urgências no Sistema Único de Saúde (SUS). [acesso em: 22 abr 2015]. Disponível em: http://bvsms.saude.gov.br/bvs/saudelegis/gm/2011/prt1600_07_07_2011.html.

2. Portaria № 1.010 Ministério da Saúde, de 21 de maio de 2012 (BR). Redefine as diretrizes para a implantação do Serviço de Atendimento Móvel de Urgência (SAMU 192) e sua Central de Regulação das Urgências, componente da Rede de Atenção às Urgências. [acesso em: 18 mai 2014] Disponível em: http://bvsms.saude.gov.br/bvs/ saudelegis/gm/2012/prt1010_21_05_2012.html.

3. Brasil. Lei № 7.498, de 25 de junho de 1986. Dispõe sobre a regulamentação do exercício da enfermagem, e dá outras providências. Diário Oficial da União. 26 Jun. 1986 [acesso em: 25 fev 2014]. Disponível em: http://novo. portalcofen.gov.br/lei-n-749886-de-25-de-junho-de-1986_4161.html.

4. Brasil. Lei 5.905, de 12 de julho de 1973. Dispõe sobre a criação dos Conselhos Federal e Regionais de Enfermagem e dá outras providências. Diário Oficial da União. 13 Jul. 1973 [acesso em: 25 fev 2014]. Disponível em: http://novo.portalcofen.gov.br/lei-n-590573-de-12-de-julho-de-1973_4162.html.

5. Resolução $N^{\circ} 375$ do Conselho Federal de Enfermagem, de 23 de março de 2011 (BR). Dispõe sobre a presença do enfermeiro no atendimento pré-hospitalar e inter-hospitalar, em situação de risco conhecido ou desconhecido. [acesso em: 25 fev 2014]. Disponível em: http://novo.portalcofen.gov.br/resoluo-cofen-n-3752011_6500.html. 
6. Resolução $N^{\circ} 487$ do Conselho Federal de Enfermagem, de 25 de Agosto de 2015 (BR). Veda aos profissionais de enfermagem o cumprimento da prescrição médica à distância e a execução da prescrição médica fora da validade. [acesso em: 17 dez 2015]. Disponível em: http://www.cofen.gov.br/resolucao-cofen-no-4872015_33939. html.

7. Resolução No 311 do Conselho Federal de Enfermagem, de 08 de fevereiro de 2007 (BR). Aprova a reformulação do Código de Ética dos Profissionais de Enfermagem. [acesso em: 25 fev 2014]. Disponível em: http://novo. portalcofen.gov.br/resoluo-cofen-3112007_4345.html.

8. NAEMT. Atendimento pré-hospitalar ao traumatizado / NAEMT (National Association of Emergency Medical Technicians), [tradução de Diego Alfaro e Hermínio de Mattos Filho]. - Rio de Janeiro: Elsevier, 2007. p. 98.

9. Gonsaga RAT, Brugugnolli ID, Zanutto TA, Gilioli JP, Silva LFC, Fraga GP. Características dos atendimentos realizados pelo Serviço de Atendimento Móvel de Urgência no município de Catanduva, Estado de São Paulo, Brasil, 2006 a 2012. Epidemiol. Serv. Saúde [internet]. 2013 [Acesso em: 22 abr 2015]; 22(2): 317-324. Disponível em: http://scielo.iec.pa.gov.br/pdf/ess/v22n2/v22n2a13.pdf.

10. Marques GQ, Lima MADS, Ciconet RM. Agravos clínicos atendidos pelo Serviço de Atendimento Móvel de Urgência (SAMU) de Porto Alegre - RS. Acta paul. enferm. [Internet]. 2011 [Acesso em: 22 abr 2015] ; 24(2): 185191. Disponível em: http://www.scielo.br/scielo.php?script=sci_arttext\&pid=S0103-21002011000200005\&lng=en.

11. Soares RAS, Pereira APJT, Moraes RM, Vianna RPT. Caracterização das vítimas de acidentes de trânsito atendidas pelo Serviço de Atendimento Móvel de Urgência (SAMU) no Município de João Pessoa, Estado da Paraíba, Brasil, em 2010. Epidemiol. Serv. Saúde [Internet]. 2012 Dez [Acesso em: 22 abr 2015]; 21(4): 589-600. Disponível em: http://scielo.iec.pa.gov.br/scielo.php?script=sci_arttext\&pid=S1679-49742012000400008\&lng=pt.

12. Duarte SJH, Lucena BB, Morita LHM. Atendimentos prestados pelo serviço móvel de urgência em Cuiabá, MT, Brasil. Rev. Eletr. Enf. [Internet]. 2011 [acesso em: 28 fev 2014]; 13(3):502-7. Disponível em: http://www.fen.ufg.br/ revista/v13/n3/pdf/v13n3a16.pdf.

13. Pitteri JSM, Monteiro OS. Caracterização do Serviço de Atendimento Móvel de Urgência (SAMU) em Palmas-Tocantins, Brasil, em 2009. Com. Ciências Saúde. [internet]. 2010 [Acesso em: 22 abr 2015]; 21(3): 227-236. Disponível em: http://bvsms.saude.gov.br/bvs/artigos/caracterizacao_servico_atendimento_movel.pdf

14. Julien MST, Araujo OCL. Caracterização dos atendimentos prestados pelo SAMU - Serviço de Atendimento Móvel de Urgência de um município do Vale do Paraíba - SP. Rev. Eletr. Enf. Vale do Paraíba. [internet]. 2013 [Acesso em: 22 abr 2015]; 1(5): 33-50. Disponível em: http://publicacoes.fatea.br/index.php/reenvap/article/ viewArticle/1133.

15. Pereira WAP, Lima MADS. O trabalho em equipe de no atendimento pré-hospitalar à vítima de acidente de trânsito. Rev Esc Enferm USP [internet] 2009 [acesso em: 21 fev 2014]; 43(2):320-7. Disponível em: http://www. scielo.br/pdf/reeusp/v43n2/a10v43n2.pdf.

16. Bernardes A, Ramos BM, Betela Júnior J, Paiva PN. Supervisão do enfermeiro no atendimento pré-hospitalar móvel: visão dos auxiliares de enfermagem. Cienc. Cuid. Saúde [internet]. 2009 [acesso em: 25 fev 2014]; 8(1):7985. Disponível em: http://periodicos.uem.br/ojs/index.php/CiencCuidSaude/article/view/7778/ 4412.

17. Bueno AA, Bernardes A. Percepção da equipe de enfermagem de um serviço de atendimento pré-hospitalar móvel sobre o gerenciamento de enfermagem. Texto Contexto Enferm. [Internet]. 2010 [acesso em: 25 fev 2014]; 19(1):45-53. Disponível em: http://www.scielo.br/pdf/tce/v19n1/v19n1a05.pdf.

18. Pereira WAP, Lima MADS. O trabalho em equipe de no atendimento pré-hospitalar à vítima de acidente de trânsito. Rev Esc Enferm USP [internet] 2009 [acesso em: 21 fev 2014]; 43(2):320-7. Disponível em: http://www. scielo.br/pdf/reeusp/v43n2/a10v43n2.pdf. 